\title{
ANALISIS PENGGUNAAN CODE SWITCHING
}

\author{
Sahrawi ${ }^{1}$, Finny Anita ${ }^{2}$, Rodhi $^{3}$ \\ ${ }^{1}$ IKIP PGRI Pontianak ${ }^{1}$ \\ IKIP PGRI Pontianak \\ ${ }^{1}$ IKIP PGRI Pontianak \\ awihasanah@gmail.com
}

\begin{abstract}
Abstrak
Tujuan dari penelitian iniuntuk mengetahui jenis penggunaan code switching yang digunakan oleh mahasiswa program studi pendidikan bahasa inggris dan untuk mengetahui manfaat dari penggunaan code switching tersebut bagi mahasiswa dalam kelas speaking for academic presentation. Penelitian deskriptif qualitative ini dilaksanakan di IKIP-PGRI Pontianak dengan sampel penelitian dari mahasiswa semester empat. Teknik pengumpulan data yang digunakan berupa interview, observasi, dan dokumentasi. Data dianalisis menggunakan langkah yang di sarankan oleh Miles and Huberman di dalam buku Creswell.Hasil penelitian menunjukkan bahwa:(1)Terdapat tiga tipe code switching yang digunakan oleh mahasiswa bahasa inggris IKIPPGRI Pontianak semester 4 tahun ajaran 2017/2018 yaitu inter-sentential code switching dengan jumlah sebanyak 48 data,intra-sentinental code switchingdimana terdapat 35 data, dan tag switchingdengan perolehan data sebanyak 20; (2) Hasil penelitian juga menunjukkan bahwa terdapat lima fungsi penggunaan code switching didalam kelas yaitu quotations, addressee specification, reiteration, message qualification, dan personalization or objectification.
\end{abstract}

Kata Kunci: analisis, speaking, code switching

\begin{abstract}
The purpuses of this research are to know the types of code switching used by the English students and to know the use of code switching for students in the speaking for academic presentation class. The research is qualitative descriptive that is conducted in IKIP-PGRI Pontianak where the sample was forth semester students. The techniques of collecting data were interview, observation, and dokumentation. The data were analyzed by using Miles and Huberman' suggestion in Creswell. The research finding were: (1) There are three types of code switching used by forth semester of english students of IKIP-PGRI Pontianak in the academic year 2017/2018 namely inter-sentential code switching with 48 data, intra-sentinental code switching got 35 data, and tag switching with 20 data; (2) the finding also showed that there are five functions of code switching in the classroom they are quotations, addressee specification, reiteration, message qualification, and personalization or objectification.
\end{abstract}

Key words: analyses, speaking, code switching

\section{PENDAHULUAN}

Bahasa berfungsi sebagai alat untuk melakukan komunikasi atau interaksi sosial dengan masyarakat. Disamping itu, bahasa juga dijadikan sebagai identitas dari sebuah masyarakat, karena dengan bahasa yang dimiliki maka secara otomatis melekat pada diri pengguna bahasa tersebut dimana bahasa itu sebagai identitas. Bahasa terjadi ketika ada kesepakatan antar semua pengguna bahasa. Saussure 
dalam buku Given (2008: 807) mengatakan bahwa bahasa merupakan sebuah kesepakatan antar pengguna bahasa atau mengetahui kode yang telah disepakati bersama untuk digunakan dalam berkomunikasi.

Bahasa juga dapat dikategorikan sebagai sebuah sistem dalam melakukan komunikasi bagi manusia (Richards and Schmidt, 2010:311). Para ahli bahasa mengkaji bahasa secara internal maupun secara eksternal. Kajian secara internal, dapat diartikan bahwa pengkajian itu hanya dilakukan terhadap struktur intern bahasa itu saja, seperti struktur fonologisnya, struktur morfologisnya, atau struktur sintaksisnya. Kajian secara internal fokus pada bagian-bagian bahasa itu sendiri tanpa ada hubungan dengan masalah lain di luar bahasa. Sebaliknya, kajian secara eksternal berarti kajian itu dilakuakan terhadap faktor-faktor yang berada di luar bahasa yang berkaitan dengan pemakaian bahasa yang digunakan oleh para penuturnya.Dengan kata lain, bahasa sebenarnya bukanlah sekedar sebagai barangatau objek dari ilmu pengetahuan manusia, melainkan proses interaksi yang dilakukan oleh manusia dalam kehidupan sehari-hari.

Fungsi umum bahasa adalah alat komunikasi dalam kehidupan sosial. Bahasa merupakan aspek yang penting dalam kehidupan manusia (Brown, 2007:26). Dengan bahasa,maka masyarakat dapatmelakukan komunikasi, interaksi serta saling berhubungan antar anggota.Sehingga untuk keperluan sehari-hari makamanusia memerlukan media yang dinamakan bahasa. Dengan demikian, setiap masyarakat dipastikan memiliki dan menggunakan bahasa sebagai alat komunikasi sosial. Sehingga masyarakat dan bahasa tidak dapat dipisahkan. Dengan kata lain, tidak ada masyarakat yang tidak memiliki bahasa dan tidak ada pula bahasa yang tanpa adanya masyarakat yang menggunakan. Dari sini dapat di pahami bahwa bahasa merupakan alat komunikasi yang digunakan manusia dalam kehidupan sehari-hari, karena melalui bahasa manusia dapat melakukan interaksi dengan orang lain untuk mengetahui informasi-infomasi yang dibutuhkan. Bahasa muncul serta berkembang disebabkan karena adanya interaksi antar individu dalam suatu masyarakat.

Dalam studi kebahasaan, dikenal adanya ilmu linguistik, yakni ilmu yang mempelajari dengan rinci sebuah bahasa yang digunakan manusia secara ilmiah. 
Wardhaugh (2006: 26) mengatakan bahwa lisnguistics fokus pada penjelasan secara tepat dari bagian kebahasaan seperti bunyi, sillabel, kata, kalimat, dan bahasa. Pada perkembangan selanjutnya, ilmu linguistik juga mempunyai beberapa cabang keilmuan. Hal ini terjadi dikarenakan bersinggungan dengan ilmu ilmu lain. Beberapa cabang linguistik itu antara lain (1) psikolinguistik adalah ilmu yang terbentuk karena perpaduan antara ilmu linguistik dengan psikologi, dimana ilmu ini fokus pada bahasa manusia dan psikologi seseorang yang mempelajari atau menggunakan bahasa tersebut, (2) sosiolinguistik, yang merupakan gabungan dari ilmu sosiologi yang artinya kehidupan sosial masyarakat pengguna bahasa dengan linguistik atau bahasa dari masyarakat itu sendiri.

Di samping itu linguistic juga bisa diklasifikasikan berdasarkan tujuan pokoknya menjadi linguistik murni (pure linguistics) dan linguistik terapan (applied linguistics). Linguistik murni mempelajari bahasa secara umum dengan tujuan utama memberikan deskripsi mengenai bahasa guna memperoleh gambaran tentang aspek-aspek bahasa seperti fonologi, morfologi, sintaksis dan semantik. Sementara linguistik terapan dirtikan sebagai ilmu yang mencoba menerapkan prinsip prinsip atau teori-teori linguistik untuk kepentingan praktis. Wardhaugh and Fuller (2015:399) mengatakan bahwa applied linguistics digunakan dalam istilah belajar mengajar.

Code switching merupakan fenomena yang sering terjadi dalam komunikasi atau penggunaan bahasa. Hal tersebut juga dialami oleh seseorang yang sedang belajar bahasa. Secara umum, code switching terjadi dikarenakan kurangnya kemampuan peserta didik dalam penguasaan bahasa yang dipelajari. Ketika peserta didik ingin berkomunikasi terdapat beberapa kata atau prase yang belum di ketahui sehingga pembicara memasukkan bahasa yang lebih familiar bagi mereka. Hal ini senada dengan (Brown, 2007:72) yang mengatakan bahwa code switching adalah sebuah tindakan memasukkan kata, prase, atau bagian dalam percakapan yang lebih panjang ke dalam bahasa yang lain. Fenomena inilah yang menjadi dasar bagi peneliti untuk melakukan penelitian tentang alih kode (code switching) agar dapat menemukan permasalahan yang terjadi secara lebih detail. 
Bahasa inggris sebagai bahasa asing di Indonesia memiliki tantangan tersendiri bagi mahasiswa yang mempelajarinya sehingga tidak sedikit dari mereka yang sering menggabungkan atau mencampur dengan bahasa Indonesia ketika mereka sedang berbicara atau presentasi. Hal tersebut juga dipengaruhi oleh latar belakang pendidikan mahasiswa yang berbeda-beda sehingga pengetahuan berbahasa mereka pun beraneka ragam. Terlebih lagi dengan beraneka ragamnya suku dan budaya mahasiswa IKIP-PGRI Pontianak, hal yang demikian itulah yang juga menjadi penyebab mahasiswa sering menggunakan bahasa yang bercampurcampur antara bahasa Inggris, bahasa Indonesia maupun bahasa daerah mereka masing-masing. Faktor tersebut juga juga menjadi penyebab terjadinya proses alih kode (code switching) dalam penggunaan bahasa Inggris.

Kode adalah istilah yang dapat mengacu kepada bahasa, dialek, sosiolek, atau ragam bahasa. Kode merupakan sebuah tanda yang digunakan dalam bahasa dengan tujuan tertentu. Alih kode sering kali terjadi didalam komunikasi seseorang yang masih belum menguasai bahasa yang sedang digunakan. Alih kode terjadi sesuai dengan kondisi masyarakat (Wardhaugh, 2010:104). Alih kode dapat terjadi dalam sebuah percakapan ketika seorang pembicara menggunakan sebuah bahasa dan mitra bicaranya menjawab dengan bahasa lain. Hal ini senada dengan Richards and Schmidt(2010:89) yang mengatakan bahwa dalam hal ini pembicara mengubah unsur-unsur bahasa lain ketika sedang memakai bahasa tertentu.

Adapun faktor lain yang menjadi dasar penelitian ini yaitu karena masyarakat Indonesia yang pada umumnya merupakan masyarakat dwibahasa atau masyarakat multilingualyaitu masyarakat yang mempunyai beberapa bahasa contoh (B1) adalah bahasa ibu, (B2) adalah Bahasa Indonesia dan di tambah dengan (B3) yaitu bahasa asing baik bahasa Inggris maupun bahasa lain. Penggunaan dua bahasa atau lebih dalam peristiwa komunikasi merupakan fenomena yang biasa terjadi di Indonesia. Dikatakan demikian karena orang-orang yang terlibat dalam tindak komunikasi paling tidak menguasai lebih dari satu bahasa, misalnya bahasa regional (bahasa Lampung, Jawa, Madura, Bali, Batak, Bugis dan sebagainya), bahasa pertama (bahasa Indonesia), dan bahasa asing (Inggris, Arab, dan sebagainya). 
Sebagai akibat dari situasi kedwibahasaan dalam proses pembelajaran pada mahasiswa IKIP-PGRI Pontianak program studi pendidikan bahasa inggris, maka terdapat faktor-faktor penentu dalam pengambilan keputusan pada sebuah tuturan. Selain itu, adanya kontak bahasa di kelas juga menyebabkan munculnya gejala alih kode pada penuturnya. Dengan kata lain, gejala kebahasaan tersebut (alih kode) mengacu pada peristiwa dimana pada saat berbicara, masih banyak mahasiswa yang memasukkan unsur-unsur bahasa lain kedalam bahasa yang sedang digunakannya yaitu bahasa inggris. Fenomena tersebut terjadi pada proses pembelajaran di kelas dan ketika mahasiswa sedang bercakap-cakap menggunakan bahasa inggris di lingkungan kampus IKIP-PGRI Pontianak maupun ketika mahasiswa mengikuti serangkaian ujian tugas akhir baik seminar proposal maupun ujian skripsi.

Program studi pendidikan bahasa inggris adalah salah satu jurusan di IKIPPGRI Pontianak yang fokus pada salah satu bahasa internasional yaitu bahasa inggris. Program studi tersebut memiliki tujuan untuk menghasilkan mahasiswa yang cakap dan terampil dalam berkomunikasi menggunakan bahasa inggris agar lulusan yang dihasilkan dapat menggunakan bahasa inggris secara efektif. Oleh karena itu, salah satu mata kuliah yang di anggap dapat membentuk dan mengasah kemampuan komunikasi bahasa inggris mahasiswa IKIP-PGRI Pontianak adalah speaking for academic presentation. Secara umum tujuan pengajaran mata kuliah ini adalah agar mahasiswa mampu menggunakan bahasa tersebut secara aktif dan profesional.

\section{METODE PENELITIAN}

Penelitian ini merupakan penelitian kualitatif yang bertujuan untuk mengekspos secara rinci fenomena yang terjadi (Creswell, 2009:92; 2012:130). Kajian bahasa yang digunakan dalam kelas speaking for academic presentation menjadi fokus dalam penelitian ini karena mahasiswa dalam kelas sering menggunakan kalimat yang dicampur antara bahasa indonesia dan bahasa inggris ketika melakukan komunikasi atau presentasi.Jenis penelitian ini adalah deskriptif kualitatif. Penelitian ini menjelaskan bagaimana siswa menggunakan pencampuran kode dalam percakapan mereka. Data dikumpulkan dengan teknik interview.Interview digunakan untuk mencari informasi yang masih belum jelas 
dari partisipan (Hatch, 2002:91).Teknik pengumpulan yang kedua adalah pengamatan. Hatch (2002: 72) mengatakan bahwa observasi merupakan proses pengumpulan data untuk memahami budaya, tempat, phenomena social yang terjadi melalui pandangan partisipan.Pengumpulan data yang ketiga adalahrekaman atau dokumentasi.Proses pengumpulan data dilakukan melalui beberapa metodeuntuk menjaga validitas data. Langkah tersebut juga dilakukan untuk memperoleh data yang di inginkan dalam penelitian (Creswell, 2009:17).

Populasi menurut Given (2008:644) lebih mudah di pahami apabila di bandingkan dengan sample karena sampel merupakan bagian darir populasi. Populasi penelitian ini adalah 108 mahasiswa. Jumlah mahasiswa semester empat ini dibagi menjadi empat kelas. Kelas tersebut terdiri dari kelas A Pagi, B Pagi, A Sore, dan B Sore. Sedangkan sampel dari penelitian ini adalah kelas A Pagi yang berjumlah 26 orang. Penentuan sampel dilakukan secara purposive agar peneliti dapat fokus pada participant dengan jumlah yang relatif kecil agar data yang diperoleh bisa lebih dalam (Given, 2008:644; Creswell, 2008: 214).

Dalam penelitian kualitative terdapat beberapa langkah dalam menganalisa data. Dalam penelitian ini, peneliti fokus pada langkah yang di sarankan oleh Miles and Huberman di dalam buku Creswell (2007:148). Adapun beberapa langkah yang dilibatkan dalam penelitian qualitative yaitu peneliti harus mempersiapkan dan menyusun data untuk dianalisa (Creswell, 2009:261). Pertama, reduksi data (data reduction), langkah yang diambil dalam tahap ini yaitu menyeleksi, memfokuskan dan menyederhanakan data mana yang akan diambil dalam penelitian.

Dalam tahap ini juga dilakukan koding data. Koding merupakan tahapan dalam menganalisa data berdasarkan kategori (Richards and Scmidt, 2010:89). Kedua, penyajian data (data display), dalam tahap ini data yang telah terkumpul dikelompokan dalam beberapa bagian sesuai dengan jenis kategori dari data yang diperoleh supaya mudah dilihat, dimengerti dan dianalisa, sehingga peneliti dapat menarik kesimpulan yang tepat dari hasi penelitian.Tahap yang ketiga yaitu kesimpulan atau verifikasi (conclusion drawing atau verification). Sebagai langkah 
yang terakhir, maka data dianalisis berdasarkandata yang diperoleh dari peserta didik selama proses penelitian.

\section{HASIL PENELITIAN DAN PEMBAHASAN}

Penelitian ini dilakukan selama proses belajar mengajar mata kuliah speaking for academic presentation untuk mengetahui jenis penggunaan code switching serta manfaat dari penggunaannya tersebut. Hasil penelitian tersebut menunjukkan bahwa terdapat tiga macam jenis code switching yang digunakan oleh mahasiswa yaitu inter-sentential code switching, tag switching, and intra-sentential code switching. Data diatas sesuai dengan pendapat Poplack (2004) yang menyatakan bahwa terdapat tiga tipe penggunaan code switching yaitu inter-sentential, intrasentential, dan tag-switching. Penelitian ini juga menemukan bahwa terdapat lima fungsi dari penggunaan code switching tersebut yaitu quotation, addressee specification, reiterations, message qualification, dan personalization or objectification. Data dari dokumentasi juga memberikan informasi yang mendukung terhadap data penelitian dan diperkaya juga melalui data obervasi yang telah dilakukan sebanyak empat kali selama 45 menit dengan waktu yang diacak selama proses belajar mengajar.

\section{Tipe Code Switching}

Terdapat beberapa jenis code-switching yang digunakan oleh mahasiswa didalam kelas yaitu inter-sentential code switching, tag switching, and intra-sentential code switching.

Table 1 Tipe Code Switching

\begin{tabular}{lll}
\hline No & \multicolumn{1}{c}{ Type of Code Switching } & Data \\
\hline 1 & Inter-sentential Switching & 48 \\
\hline 2 & Intra-sentential Switching & 35 \\
\hline 3 & Tag Switching & 20 \\
\hline
\end{tabular}

Tabel diatas menunjukkan bahwa data yang diperoleh dari penelitian terdiri dari beberapa tipe code-switching yaitu tipe pertama adalah inter-sentential yang terdiri dari 48 data, tipe yang kedua yaitu intra-sentential code switching dimana data yang 
diperoleh sebanyak 35 data, dan tipe yang terakhir yaitu tag switching dengan data yang diperoleh sebanyak 20 data.

\section{A. Inter-sentential switching}

Inter-sentential switching adalah sebuah proses peralihan klausa atau kalimat dalam satu bahasa. Inter-sentential switching sering terjadi dalam proses belajar mengajar di kelas karena pembicara dalam hal ini mahasiswa melakukan code switching karena mereka merasa perlu untuk mengklarifikasi atau mengartikan apa yang diucapkan sebelumnya. Hasil dari analisa data menunjukkan bahwa inter-sentential switching merupakan salah satu tipe yang paling banyak muncul yaitu dengan 48 data dari total 103 data.

\section{B. Intra-sentential switching}

Tipe code switching yang kedua yaitu intra-sentential switching. Tipe ini dilakukan oleh seseorang dalam melakukan komunikasi dengan mengalihkan kata didalam kalimat. Dengan kata lain, code switching tipe ini terjadi dalam kalimat pembicara ketika sedang melakukan proses belajar mengajar. Hasil penelitian menunjukkan bahwa terdapat 35 data yang dapat dikategorikan sebagai tipe intra-sentinental switching.

\section{Tag Switching}

Tipe code switching yang ketiga adalah tag switching dimana pembicara memasukkan kata singkat untuk melakukan penekanan dalam pembicaraanya. Proses yang terjadi saat kelas mata kuliah speaking for academic presentation sedang berlangsung menunjukkan bahwa mahasiswa melakukan tipe ini ketika mereka ingin meyakinkan pembicaraannya dengan menyelipkan kata singkat. Mahasiswa memasukkan kata pendek sebagai tanda penekanan dari apa yang disampaikannya. Hasil penelitian menemukan terdapat 20 data penggunaan tipe tag code switching ini.

\section{Funsi dari Code Switching}

Bagian kedua dari data penelitian menunjukkan bahwa penggunaan code switching tersebut memiliki fungsi tersendiri bagi pembicara. Dengan kata lain, pembicara menggunakan code switching untuk tujuan tertentu. Adapun hasil penelitian menunjukkan bahwa terdapat lima fungsi dari penggunaan code switching yang 
digunakan oleh mahasiswa bahasa inggris selama mengikuti kelas speaking for academic presentation, khususnya ketika mereka melakukan presentasi di depan kelas. Kelima fungsi dari penggunaaan code switching tersebut adalah sebagai berikut: Quotation, Addressee specification, Reiterations, Message qualification, dan Personalization or Objectification.

Tabel 2 Fungsi Penggunaan Code Switching

\begin{tabular}{lll}
\hline No & Fungsi Penggunaan Code Switching & Data \\
\hline 1 & Quotation & 6 \\
\hline 2 & Address Specification & 20 \\
\hline 3 & Reiteration & 35 \\
\hline 4 & Messege Qualification & 27 \\
\hline 5 & Personalization or Objectification & 15 \\
\hline \multicolumn{2}{c}{ Total } & $\mathbf{1 0 3}$ \\
\hline
\end{tabular}

Tabel diatas menunjukan bahwa penggunaan code switching sesuai tujuan dari pembicara diperoleh sebanyak 103 data. Hasil tersebut merupakan kumpulan dari beberapa sumber pengumpulan data yang diperoleh selama proses penelitian berlangsung. Penggunaan code switching dengan tujuan quotation diperoleh 6 data, fungsi penggunaan dengan kategori addressee specification menunjukkan terdapat 20 data. Tujuan menggunakan code switching yang selanjutnya yaitu reiteration dengan data yang paling banyak keluar atau paling sering digunakan oleh mahasiswa dalam melakukan komunikasi. Fungsi reiterationmenunjukkan terdapat 35 data yang diperoleh dalam penelitian. Jenis fungsi yang ke empat yaitu message qualification dengan 27 data and fungsi yang terakhir yaitu personalization or objectification sebanyak 15 data.

\section{a. Quotation}

Fungsi dari penggunaan code switching sebagai quotation adalah untuk menggantikan kata dengan menggunakan bahasa asli dari kutipan yang digunakan atau bahasa yang dimaksud. Dengan kata lain, kegunaan dari jenis ini yaitu ketika seseorang yang memiliki kemampuan dua bahasa atau bilingualdimana seseorang penyampaikan pembicaraannya menggunakan bahasa asli dari yang dimaksud oleh pembicara. 


\section{b. Addressee specification}

Fungsi yang kedua dari penggunaan code switching adalah addressee specification. Penggunaan tipe ini bertujuan untuk memberikan atau menarik perhatian peserta atau pendengar terhadap apa yang disampaikan oleh pembicara. Tipe ini juga seringdilakukan oleh mahasiswa ketika mereka menyampaikan materi di depan kelas dalam mata kuliah speaking for academic presentation.

\section{c. Reiterations}

Penggunaan code switching dapat terjadi secara disengaja dan secara spontan ketika seseorang sedang berbicara atau berkomunikasi. Adapun penggunaan tipe reiteration initerjadi ketika seseorang mengulang apa yang telah disampaikan untuk mengklarifikasi atau memberikan tekanan terhadap informasi apa yang sudah dikatakan. Dari hasil penelitian diperoleh data sebanyak 35.

\section{d. Message qualification}

Fungsi code switchingsebagai message qualification bertujuan untuk membatasi apa yang sedang disampaikan oleh pembicara. Pembicara menggunakan code switching karena mereka ingin meyakinkan pendengar bahwa pendengar mengerti informasi mana dan bagian apa yang dimaksud oleh pembicara.

\section{e. Personalization or Objectification}

Fungsi kelima dari code switchingyang digunakan oleh mahasiswa ketika melakukan presentasi di dalam kelas yaitu personalization or objectification. Penggunaan fungsi ini untuk melakukan komunikasi atau menyampaikan apa yang ada didalam pikiran pembicara tentang suatu hal atau keadaan.

\section{SIMPULAN}

Berdasarkan penelitian yang telah dilakukan dalam mata kuliah speaking for academic presentation maka dapat disimpulkan bahwa terdapat tiga tipe codeswitching dan lima fungsi penggunaan code-switchingdalam melakukan komunikasi menggunakan bahasa inggris di kelas.

1. Tipe code switching yang digunakan oleh mahasiswa bahasa inggris IKIP-PGRI Pontianak semester 4 tahun ajaran 2017/2018.

Hasil penelitian menunjukkan bahwa terdapat tiga tipe code switchingyang digunakan oleh mahasiswa yaitu inter-sentential code switching. Pembicara 
menggunakan tipe ini untuk mengklarifikasi pembicaraan sebelumnya. Sementara tipe yang kedua yaitu intra-code switching. Tipe ini digunakan oleh mahasiswa dalam komunikasi dimana tujuan penggunaan tipe ini untuk membatasi kalimat yang disampaikan. Tipe yang terakhir yaitu tag switchingdimana penggunaan tipe ini merupakan tipe yang muncul paling sedikit dalam penelitian. Pembicara menggunakan tipe ini untuk melakukan penekanan kalimat yang diucapkan.

. Fungsi penggunaan code switching oleh mahasiswa program studi bahasa inggris IKIP-PGRI Pontianak.

Hasil penelitian menunjukkan bahwa terdapat lima fungsi penggunaan code switching yaitu quotations dimana pembicara menggunakan code switching untuk menyampaikan pembicaraan secara langsung menggunakan bahasa asal kutipan. Fungsi yang kedua adalah addressee specification. Tujuan dari penggunaan code switching yaitu untuk menjelaskan secara lebih terperinci pembicaraan yang disampaikan. Fungsi yang ketiga yaitu reiteration. Pembicara menggunakan code switching untuk menjelaskan perkataan sebelumnya. Fungsi yang ke empat adalahmessage qualification berfungsi untuk menjelaskan meteri tertentu dan memberikan penjelasan lanjutan terhadap ungkapan selanjutnya.Fungsi yang terakhir adalahpersonalization atauobjectification bertujuan untuk menjelaskan tentang sesuatu yang nyata dan bersifat pendapat pribadi dari pembicara.

\section{DAFTAR PUSTAKA}

Brown,H.D. (2007). Principles of Language Learning and Teaching. New York: Pearson Education, Inc.

Creswell, J. W. (2007). Qualitative Inquiry and Research Design (2 ${ }^{\text {nd }}$ Edition). London: Sage Publications.

Creswell, J.W. (2008). Educational Research: Planning, Conducting, and Evaluating Quantitative and Qualitative Research ( $3^{\text {rd }}$ Edition). New Jersey: Pearson Education, Inc.

Creswell, J.W.(2009). Research Design: Qualitative, Quantitative, and Mixed Methods Approaches ( $3^{\text {rd }}$ Edition). London: SAGE Publications, Inc. 
Creswell, J.W.(2012). Educational Research: Planning, Conducting, and Evaluating Quantitative and Qualitative Research (4 ${ }^{\text {th }}$ Edition). Boston: Pearson Education, Inc.

Given, L.M. (2008). The SAGE Encyclopedia of Qualitative Research Method. Californa: Sage Publication,Inc.

Hatch, J.A. (2002). Doing Qualitative Research In Education Settings. New York: State University of New York Press, Albany.

Poplack, S. (2004). Code Switching / Soziolinguistik: An International Handbook of the Science of Language and Society. Berlin: Walter de Gruyter.

Richards, J.C dan Schmidt, R. (2010). Longman Dictionary of Language Teaching and Applied Linguistics. Great Britain: Pearson Education Limited.

Wardhaugh, R. (2010). An Introduction to Sociolinguistics. Oxford: Blackwell Publisher.

Wardhaugh, R. (2006). An Introduction to Sociolinguistics. USA: Blackwell Publisher.

Wardhaugh, R., \& Fuller J, M. (2015). An Introduction to Sociolinguistics. United Kingdom: John Wiley \& Sons, Inc. 